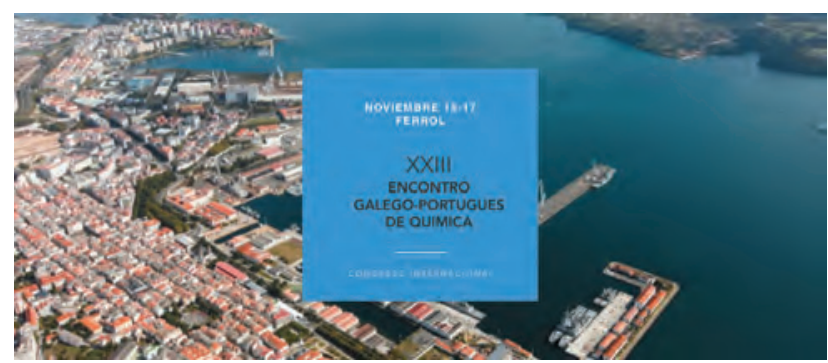

\section{Encontro Galego-Portugués de Química}

O XXIII Encontro Galego-Portugués de Química será organizado pelos nuestro hermanos de Ferrol, na Galiza (Espanha), entre 15 e 17 de novembro de 2017. Aquele que é um encontro emblemático da cooperação entre a Sociedade Portuguesa de Química e o Colegio Oficial de Químicos de Galicia, celebrará a XXIII edição destes encontros que se iniciaram em novembro de 1985 e que ocorrem, alternadamente, entre Portugal e a Galiza

Cada Encontro procurou e procura favorecer e fortalecer o intercâmbio científico e tecnológico entre os agentes provenientes das universidades e/ou empresas entre a Galiza e Portugal. A participação no evento é possível mediante registo até 21 de outubro (sem custos adicionais) e submissão de resumos para comunicação até 26 de setembro. Os idiomas oficiais serão o castelhano, português, galego e inglês.

www.encontrogalegoportugues.org

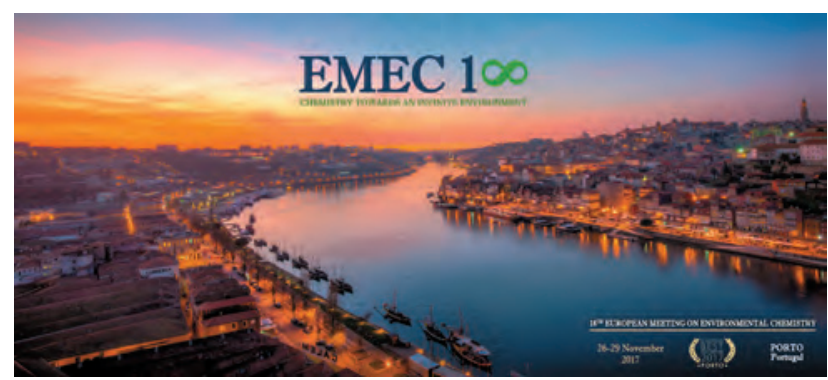

$18^{\text {th }}$ European Meeting on Environmental Chemistry

A conferência European Meeting on Environmental Chemistry (EMEC) tem lugar anualmente sob a égide da Association of Chemistry and the Environment (ACE). Este ano cabe ao Departamento de Engenharia Química, da Faculdade de Engenharia da Universidade do Porto (FEUP), a honra de organizar a 18. ${ }^{a}$ edição no Porto, de 26 a 29 de novembro de 2017. Sob o mote "Chemistry towards an Infinite Environment", o EMEC18 continuará a tradição de encontros anteriores, na esperança de contribuir para uma sustentabilidade duradoura do nosso planeta. Proporcionará um amplo fórum para o intercâmbio de ideias sobre progressos recentes nas áreas da química e tecnologias ambientais. Os principais tópicos do evento são: Monitorização ambiental (métodos analíticos para a ciência ambiental; água, ar, solo e biota); Tecnologias ambientais (processos convencionais e avançados de tratamento; gestão e reciclagem de resíduos); Modelação ambiental; Desenvolvimento sustentável (exposição e avaliação de riscos; análise do ciclo de vida; economia circular); Segurança ambiental (ecotoxicologia e biomarcadores); e Processos agroambientais amigáveis e química alimentar. O encontro EMEC atrai sempre apresentações científicas de alta qualidade de cientistas de renome internacional e de jovens investigadores; os trabalhos de cariz interdisciplinar são bem-vindos. emec18.eventos.chemistry.pt

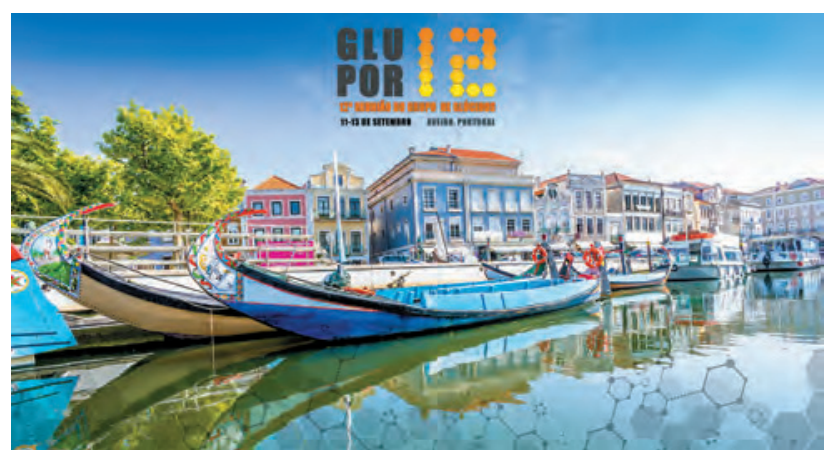

\section{2.ํㅡㄹ Encontro Nacional do Grupo da Química dos Glúcidos}

Realizar-se-á de 11 a 13 de setembro de 2017, na Universidade de Aveiro, aquele que será o 12. ${ }^{\circ}$ Encontro Nacional - Glupor-12 — do Grupo de Glúcidos da Sociedade Portuguesa de Química.

A um ano de distância da organização do International Carbohydrate Symposium, a realizar de 25 a 30 de julho de 2018 em Lisboa, esta é uma ocasião de reunião da comunidade portuguesa em torno da ciência dos carboidratos com o tema "Carboidratos em Portugal e potencial de diferenciação internacional”. Serão abordadas temáticas abrangentes e transversais às áreas da Química, Bioquímica, Farmacêutica e Ciências da Saúde, Têxteis, Compostos Celulósicos, Ciência de Materiais, Ciência dos Alimentos e Ciências Sociais e Humanas.

As inscrições para o evento, sem penalização no custo de registo, encontram-se abertas até 15 de julho do corrente ano. glupor12.eventos.chemistry.pt

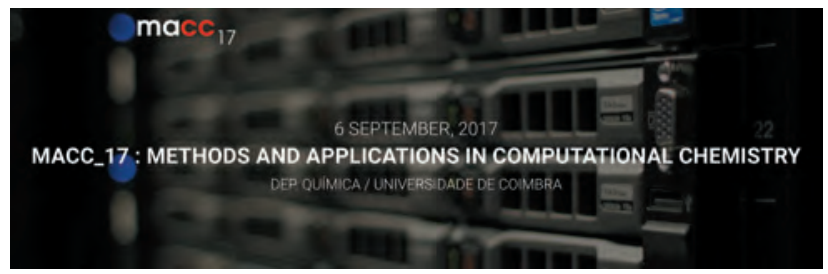

MACC_2017: Methods and Applications in Computational Chemistry

Foi recentemente criado o Grupo de Química Computacional da SPQ com o objetivo de interligar a comunidade portuguesa de investigadores nesta área. De modo a contribuir para a dinamização da troca de experiências e divulgação do trabalho desenvolvido, será realizado um encontro de um dia (6 de setembro de 2017), na Universidade de Coimbra, intitulado MACC_17: Methods and Applications in Computational Chemistry. Os tópicos a debater incluirão métodos de química computacional e suas aplicações às mais variadas áreas. As palestras serão apresentadas em inglês.

Para estender a participação ao maior número possível de jovens investigadores interessados, a inscrição no evento não tem quaisquer custos, mas é obrigatória, em macc17.qui.uc.pt. macc17.qui.uc.pt 